\title{
Primary site surgery for metastatic adrenocortical carcinoma improves survival outcomes: an analysis of a population-based database
}

This article was published in the following Dove Press journal:

OncoTargets and Therapy

8 November 2017

Number of times this article has been viewed

\author{
Sen Wang \\ Wei-Cheng Gao \\ San-San Chen \\ Liang Bai \\ Li Luo \\ Xiang-Guang Zheng \\ You Luo
}

Department of Urology, The First Affiliated Hospital of Guangdong

Pharmaceutical University, Guangzhou, China
Correspondence: You Luo Department of Urology, The First Affiliated Hospital of Guangdong Pharmaceutical University, No 19 Nonglinxia Street, Guangzhou 510080, China

Fax +860206I3354I7

Email luoyou@mail3.sysu.edu.cn
Objective: To define the survival effect of surgery of primary adrenal malignant lesions in metastatic adrenocortical carcinoma (ACC) patients.

Patients and methods: We used the Surveillance, Epidemiology and End Results (SEER) database (1973-2014) to identify metastatic ACC patients (stage IV by using European Network for the Study of Adrenal Tumors stage classification). Correlated variables, including age, sex, race, tumor laterality, treatment modality, lymph node dissection, surgery of metastatic site, tumor size, and tumor stage, were extracted. Univariate and multivariate Cox regression analyses were used to define the efficacy of surgery on survival outcomes, including overall survival and cancer-specific survival of ACC.

Results: There were 290 metastatic ACC patients identified from the database. The overall median survival time was 7 (95\% CI, 6-8) months. Among these patients, 118 patients received primary site surgery and 172 patients did not. In both univariate and multivariate analyses, primary site surgery significantly improved both overall (hazard ratio $0.413,95 \% \mathrm{CI}$, 0.299-0.571, $P<0.01$ ) and cancer-specific survival (hazard ratio $0.408,95 \% \mathrm{CI}, 0.290-0.574$, $P<0.01)$ for metastatic ACC patients.

Conclusion: Our study suggests that primary site surgery in metastatic ACC patients significantly improved overall and cancer-specific survival. Further multicenter prospective studies are still needed to validate these outcomes.

Keywords: adrenocortical carcinoma, survival, metastasis, adrenalectomy

\section{Introduction}

Adrenocortical carcinoma (ACC) accounts for most primary adrenal gland malignancies. It is a fatal disease because of its rapid progression risk. ${ }^{1,2}$ Almost two-thirds of patients (pts) experienced tumor recurrence within 2 years after curative surgery, including local recurrence and metastasis. ${ }^{3}$ Surgical resection of the primary tumor is still the unique curative treatment modality for non-metastatic ACCs. ${ }^{4}$ Adjuvant therapy in conjunction with surgery could delay tumor recurrence, but the improvement in overall survival is controversial. ${ }^{5,6}$ Reoperation, mitotane therapy, and chemotherapy are the pivotal choices for advanced and recurrent ACCs. The most responsive combination therapy, etoposide, doxorubicin, cisplatin with mitotane (EDP-M), was superior to the streptozotocin with mitotane (Sz-M) regimen and had a similar incidence of adverse events in the First International Randomized Trial in Locally Advanced and Metastatic Adrenocortical Carcinoma Treatment (FIRM-ACT) trial. ${ }^{7}$ However, there is little research on the effect of surgery on metastatic ACCs. Previous studies on metastatic ACC patients are scarce due to the low incidence of ACC and lack of a 
large population. The aim of this study is to define the effect of surgery on metastatic ACCs using a population-based oncologic database.

\section{Patients and methods}

\section{Study population}

The Surveillance, Epidemiology and End Results (SEER) database (1973-2014, November 2016 submission) was queried using the International Classification of Diseases for Oncology Codes Third Edition (ICD-O-3). SEER is a national population-based registry that collects tumor-related data, including the incidence, treatment, mortality, and other demographics. This submission from 18 registries covers $\sim 27.8 \%$ of the US population. The primary query condition was histology type (ICD-O-3: 8370), resulting in 2014 cases. Then, the consecutive screen conditions were as follows: site recodeadrenal, first primary tumor with survival time, unilateral tumor, adults (age $\geq 18$ years), and finally stage IV. The clinical tumor stages were defined using the European Network for the Study of Adrenal Tumors (ENSAT) stage system. The ENSAT stage system consists of stages I $\left(\mathrm{T}_{1} \mathrm{~N}_{0} \mathrm{M}_{0}\right)$, II $\left(\mathrm{T}_{2} \mathrm{~N}_{0} \mathrm{M}_{0}\right)$, III $\left(\mathrm{T}_{1-2} \mathrm{~N}_{1} \mathrm{M}_{0}\right.$ or $\left.\mathrm{T}_{3-4} \mathrm{~N}_{0-1} \mathrm{M}_{0}\right)$, and IV $\left(\mathrm{T}_{\text {any }} \mathrm{N}_{\text {any }} \mathrm{M}_{1}\right) \cdot{ }^{8,9}$ Stage IV means metastatic ACC (tumor implants to distant organ or tissues, such as the liver, lung, and bone). Considering some underutilized data (eg, collaborative stages of tumor extension, tumor size, lymph nodes, and metastasis at diagnosis, but no concluded tumor stage), we restaged the TNM stage compatible with the Union for International Cancer Control/American Joint Committee on Cancer stage system based on the Collaboration Stage Data Collection System version 02.05 (CS version 02.05, http://web2.facs.org/cstage0205/adrenalgland/ AdrenalGlandschema.html). After multiple rounds of screening, 290 records were identified. Related variable information was extracted, including age, sex, race, tumor size, tumor laterality, treatment modality (surgery or not, chemotherapy or not, radiotherapy or not), regional lymph node dissection (RLND, defined as codes 3-7, regional lymph nodes removed regardless of quantity), tumor size, tumor stage, cause of death, survival status, and survival time. Endpoint outcomes included overall survival and cancer-specific survival. This study was deemed exempt from the institutional review board approval of the First Affiliated Hospital of Guangdong Pharmaceutical University because the data were from a public health database accessible to applicants.

\section{Statistical analysis}

Basic demographic characteristics and tumor-related information are described. Continuous variables are presented as median with interquartile range (IQR) in parentheses.
Category variables are presented as counts. We used the Kaplan-Meier method to estimate survival time and the Breslow (Wilcoxon) test to test the equality of survival functions. For regression survival analysis, we used univariate regression analysis to screen potential confounding variables. Variables with $P \leq 0.1$ in univariate analysis were included in the multivariate Cox regression. The hazard ratio (HR) and 95\% CI were used to show the risks of overall and cancerspecific mortality. The Cox proportion hazard assumption tests were performed using the Schoenfeld residuals method. All tests were two-sided, and a $P$-value of $<0.05$ was considered statistically significant. All statistical analyses were performed by using Stata 14 and R software (Version 3.3.3, https://www.r-project.org).

\section{Results}

The demographic characteristics are shown in Table 1. A total of 290 metastatic ACC patients with a median age of 55 years (IQR 42-65) were identified between 2004 and

Table I Demographic characteristics of the study population

\begin{tabular}{|c|c|c|c|}
\hline \multirow[t]{2}{*}{ Variables } & \multicolumn{2}{|c|}{ Surgery of primary site } & \multirow[t]{2}{*}{$P$-value } \\
\hline & $\begin{array}{l}\text { No } \\
(n=\mid 72)\end{array}$ & $\begin{array}{l}\text { Yes } \\
(n=|| 8)\end{array}$ & \\
\hline Age (year) & $56.45 \pm 15.37$ & $52.15 \pm 13.96$ & $<0.01$ \\
\hline Tumor size $(\mathrm{cm})$ & II. $.33 \pm 4.94$ & $13.56 \pm 6.42$ & $<0.01$ \\
\hline Sex & & & 0.90 \\
\hline Female & 100 & 67 & \\
\hline Male & 72 & 51 & \\
\hline Race & & & 0.88 \\
\hline White & 143 & 101 & \\
\hline Black & 14 & 9 & \\
\hline Other & 15 & 8 & \\
\hline Laterality & & & 0.09 \\
\hline Left & 100 & 57 & \\
\hline Right & 70 & 60 & \\
\hline RLND & & & $<0.01$ \\
\hline No & 165 & 76 & \\
\hline Yes & 0 & 39 & \\
\hline $\begin{array}{l}\text { Surgery of } \\
\text { metastatic site }\end{array}$ & & & $<0.01$ \\
\hline No & 164 & 86 & \\
\hline Yes & 8 & 32 & \\
\hline Radiation & & & 0.94 \\
\hline No/unknown & 142 & 97 & \\
\hline Yes & 30 & 21 & \\
\hline Chemotherapy & & & 0.26 \\
\hline No/unknown & 74 & 43 & \\
\hline Yes & 98 & 75 & $<0.01$ \\
\hline Follow-up (months) & $3(I-7.5)$ & $8(4-20)$ & \\
\hline Vital status & & & $<0.01$ \\
\hline Alive & 10 & 29 & \\
\hline Dead & 162 & 89 & \\
\hline
\end{tabular}

Notes: Continuous variables were compared using the Welch two-sample $t$-test or Wilcoxon rank sum test. Count variables were compared using the Fisher exact test or chi-squared test. Missing values were omitted during analysis.

Abbreviation: RLND, regional lymph node dissection. 

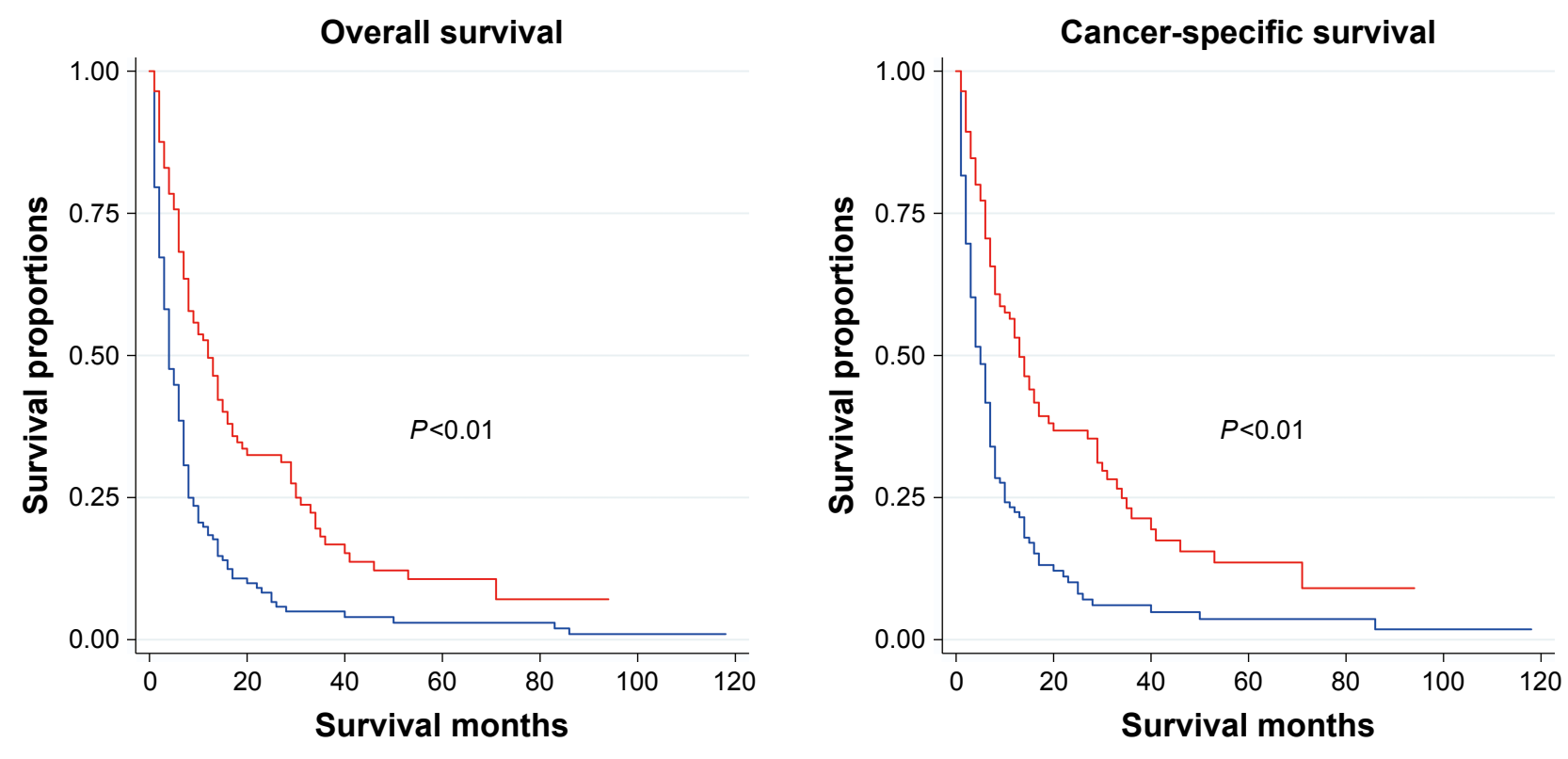

$$
\text { - No surgery — Surgery }
$$

Figure I Kaplan-Meier survival curve (overall and cancer-specific survival) of surgery of the primary site. Note: Both graphs show a significant survival difference between surgery and no-surgery groups $(P<0.0 \mathrm{I})$.

2014. The population consisted of 167 (57.6\%) female and $123(42.4 \%)$ male patients. The main race was the white race (244 pts, $84.1 \%)$. The locations of the lesions were similar (157 left and 130 right ACCs). The median tumor size was $11.8 \mathrm{~cm}(8.7-15 \mathrm{~cm})$. Treatment modality included no surgery (172 pts) and surgery (118 pts) of the primary site. RLND was performed in 39 patients. Surgery of the metastatic lesion was performed in 40 patients; 51 patients received radiation therapy; 173 patients received chemotherapy. Among the 290 patients, 251 patients died during the follow-up; 224 patients died of ACC-specific causes, and the other 27 died of other causes. The median overall survival time was 6 (95\% CI, 5-7) months. As seen in Figure 1, the median overall survival time for surgery group was 12 (95\% CI, 8-16) months and for the no-surgery group, it was 4 (95\% CI, 3-4) months (Wilcoxon $P<0.01$ ).

Table 2 shows both univariate and multivariate analyses of the overall survival and cancer-specific survival. In univariate analysis, age $(P=0.032)$, surgery of the primary site $(P<0.010)$, surgery of the metastatic site $(P=0.027)$, and chemotherapy $(P<0.01)$ were associated with overall survival. Race, sex, lymph node dissection, tumor location, tumor size, and radiotherapy were not significantly associated. In multivariate Cox regression analysis, only surgery of the primary site (HR 0.413, 95\% CI, 0.299-0.571, $P<0.01$ ) and chemotherapy (HR 0.485, 95\% CI, 0.350-0.672, $P<0.01$ ) were independent risk factors. Age, tumor size, and surgery of metastatic site had no significant effect on overall survival.
Univariate analysis showed surgery of the primary site $(P<0.010)$, surgery of the metastatic site $(P=0.045)$, and chemotherapy $(P<0.01)$ were correlated with cancer-specific survival. Multivariate analysis showed only surgery of the primary site and chemotherapy improved cancer-specific survival. Tumor size and surgery of the metastatic site did not affect the survival outcome.

\section{Discussion}

In this study, surgery of the primary site improved overall and cancer-specific survival in metastatic ACC patients. Recently published recommendations by the European Society of Endocrine Surgeons (ESES) and ENSAT did not encourage palliative or debulking surgery for metastatic ACC due to insufficient evidence. ${ }^{10}$ Our results showed a survival benefit of surgery for metastatic ACC. Due to the rarity of ACC, few studies have focused on advanced ACC. Our results are supported by the research published by Kerkhofs et al. ${ }^{11}$ In their study, a total of 189 ACC patients from the Netherlands Cancer Registry were recruited, 72 of whom were stage IV. The 34 patients who underwent surgery had longer median survival than those did not (median 10 months versus 2 months, $P<0.001)$. This outcome was in accordance with our results that the median overall survival time for the surgery group was 12 months and for the no-surgery group, it was 4 months $(P<0.01)$. Additionally, there is other circumstantial evidence for the benefit of surgery. Simon et al summarized a multicenter retrospective study of the efficacy 
Table 2 Univariate and multivariate Cox regression analyses for overall and cancer-specific survival

\begin{tabular}{|c|c|c|c|c|c|c|c|c|}
\hline \multirow[t]{3}{*}{ Variable } & \multicolumn{4}{|l|}{ Overall survival } & \multicolumn{4}{|c|}{ Cancer-specific survival } \\
\hline & \multicolumn{2}{|l|}{ Univariate } & \multicolumn{2}{|l|}{ Multivariate } & \multicolumn{2}{|l|}{ Univariate } & \multicolumn{2}{|l|}{ Multivariate } \\
\hline & Hazard ratio & $P$-value & Hazard ratio & $P$-value & Hazard ratio & $P$-value & Hazard ratio & $P$-value \\
\hline $\begin{array}{l}\text { Surgery of } \\
\text { primary site }\end{array}$ & Reference: no & & & & & & & \\
\hline Yes & $0.473(0.359-0.621)$ & $<0.01$ & $0.4 I 3(0.299-0.57 \mid)$ & $<0.01$ & $0.464(0.348-0.619)$ & $<0.01$ & $0.408(0.290-0.574)$ & $<0.01$ \\
\hline Age & $1.010(1.001-1.020)$ & 0.032 & $1.003(0.992-1.014)$ & 0.622 & $1.007(0.998-1.017)$ & 0.140 & & \\
\hline Tumor size & $0.998(0.995-1.000)$ & 0.059 & $1.000(0.997-1.003)$ & 0.946 & $0.998(0.995-1.000)$ & 0.086 & $1.000(0.997-1.003)$ & 0.916 \\
\hline Sex & Reference: male & & & & & & & \\
\hline Female & $0.854(0.655-1.115)$ & 0.246 & & & $0.857(0.648-1.133)$ & 0.280 & & \\
\hline Race & Reference: white & & & & & & & \\
\hline Black & $1.34 \mid(0.845-2.130)$ & 0.213 & & & $1.170(0.700-1.955)$ & 0.550 & & \\
\hline Other & $0.786(0.482-1.280)$ & 0.333 & & & $0.820(0.496-1.356)$ & 0.439 & & \\
\hline Laterality & Reference: left & & & & & & & \\
\hline Right & $0.808(0.616-1.058)$ & 0.121 & & & $0.820(0.617-1.088)$ & 0.169 & & \\
\hline RLND & Reference: no & & & & & & & \\
\hline Yes & $0.836(0.57 \mid-1.223)$ & 0.356 & & & $0.869(0.586-1.290)$ & 0.486 & & \\
\hline $\begin{array}{l}\text { Surgery of } \\
\text { metastatic site }\end{array}$ & Reference: no & & & & & & & \\
\hline Yes & $0.631(0.419-0.950)$ & 0.027 & $0.919(0.584-1.447)$ & 0.716 & $0.647(0.422-0.991)$ & 0.045 & $0.942(0.585-1.516)$ & 0.805 \\
\hline Radiation & Reference: no/unknov & & & & & & & \\
\hline Yes & 0.811 (0.578-I.I39) & 0.227 & & & $0.862(0.607-1.223)$ & 0.404 & & \\
\hline Chemotherapy & Reference: no/unknov & & & & & & & \\
\hline Yes & $0.545(0.4|4-0.7| 8)$ & $<0.01$ & $0.485(0.350-0.672)$ & $<0.01$ & $0.550(0.4 I 2-0.734)$ & $<0.01$ & $0.464(0.335-0.642)$ & $<0.01$ \\
\hline
\end{tabular}

of surgery on recurrent ACC and concluded better overall survival for the surgery group, ${ }^{12}$ although this conclusion was based on large selection bias. The majority of their patients with local recurrence received reoperation, while those with metastatic recurrence did not. The above literature directly or indirectly indicates the potential benefit of surgery for advanced ACC. Erdogan et $\mathrm{al}^{13}$ from the German Adrenocortical Carcinoma Study Group reached to a similar conclusion that surgery of R0 (microscopically complete resection) could decrease the disease progression and overall mortality risk, though they did not perform a deep analysis for the recurrence subgroup, which was regarded as not amenable to radical resection due to advanced disease. In this group, 23 of the 68 recurrent ACC patients (all initially underwent radical resection) underwent debulking surgery. No further comparison was performed regarding the debulking surgery. Libe et $\mathrm{al}^{14}$ investigated the prognostic factors of ENSAT stage III-IV ACC in a large cohort of 444 ACC patients (210 stage III and 234 stage IV) using the ENSAT ACC registry data. Age, tumor stage, symptoms, and resection margin status were prognostic factors. However, they did not analyze the efficacy of surgery as a variable. We recommend revisiting these relatively large cohorts to gain further insight into the efficacy of surgery.
Surgery experience is important for tumor control. The surgical margins are somewhat related to the surgeon's experience. R1 (microscopically positive) and/or R2 (macroscopically positive) patients have a poorer prognosis than R0 (microscopically negative) patients. ${ }^{15-18} \mathrm{R} 0$ is difficult to achieve, especially because extreme skill is required. In Margonis' retrospective multicenter study, $\sim 68.4 \%$ of $\mathrm{R} 0$ resection was achieved in ACC patients. ${ }^{17}$ The surgical modality is also a critical factor. The necessity of regional lymph node resection is controversial. ${ }^{19-21}$ Lymphadenectomy is not a standard procedure of adrenalectomy in ACC treatment. ${ }^{4}$ The benefit of adjuvant mitotane administration after surgery remains controversial due to the low incidence of ACC, and no large randomized trial has been performed..$^{6,722-25}$ Mitotane could be effective for certain patients. Predictors of response to mitotane therapy and other cytotoxic drugs could facilitate individualized treatment. Palliative surgery plus adjuvant medical therapy could increase survival and ameliorate related symptoms.

There are several limitations to our study. This study is based on the SEER database and therefore has the intrinsic bias of an observational study. For instance, during clinical practice, metastatic ACC patients underwent primary site surgery, which is prone to have good prognostic characteristics, 
which possibly contributed to the surgical decision. Additionally, some peri-surgery parameters, such as hormone secretion, clinical symptoms, and surgical margin status which were prognostic factors in other studies, were not included because we lacked such information. These limitations weaken the evidence of this study. Prospective multicenter collaborative studies are urgently needed to obtain highquality evidence in the future.

\section{Conclusion}

Our study suggests that primary site surgery in metastatic ACC patients significantly improved overall and cancerspecific survival. Further multicenter prospective studies are still needed to validate these outcomes.

\section{Disclosure}

The authors report no conflicts of interest in this work.

\section{References}

1. Else T, Kim AC, Sabolch A, et al. Adrenocortical carcinoma. Endocr Rev. 2014;35(2):282-326.

2. Kerkhofs TM, Verhoeven RH, Van der Zwan JM, et al. Adrenocortical carcinoma: a population-based study on incidence and survival in the Netherlands since 1993. Eur J Cancer. 2013;49(11):2579-2586.

3. Amini N, Margonis GA, Kim Y, et al. Curative resection of adrenocortical carcinoma: rates and patterns of postoperative recurrence. Ann Surg Oncol. 2016;23(1):126-133.

4. Stigliano A, Chiodini I, Giordano R, et al. Management of adrenocortical carcinoma: a consensus statement of the Italian Society of Endocrinology (SIE). J Endocrinol Invest. 2016;39(1):103-121.

5. Else T, Williams AR, Sabolch A, Jolly S, Miller BS, Hammer GD. Adjuvant therapies and patient and tumor characteristics associated with survival of adult patients with adrenocortical carcinoma. $J$ Clin Endocrinol Metab. 2014;99(2):455-461.

6. Terzolo M, Angeli A, Fassnacht M, et al. Adjuvant mitotane treatment for adrenocortical carcinoma. N Engl J Med. 2007;356(23):2372-2380.

7. Fassnacht M, Terzolo M, Allolio B, et al; FIRM-ACT Study Group. Combination chemotherapy in advanced adrenocortical carcinoma. N Engl J Med. 2012;366(23):2189-2197.

8. Lughezzani G, Sun M, Perrotte P, et al. The European Network for the Study of adrenal tumors staging system is prognostically superior to the international union against cancer-staging system: a North American validation. Eur J Cancer. 2010;46(4):713-719.

9. Fassnacht M, Johanssen S, Quinkler M, et al. Limited prognostic value of the 2004 international union against cancer staging classification for adrenocortical carcinoma: proposal for a revised TNM classification. Cancer. 2009;115(2):243-250.
10. Gaujoux S, Mihai R; joint working group of ESES and ENSAT European Society of Endocrine Surgeons (ESES) and European Network for the Study of Adrenal Tumours (ENSAT) recommendations for the surgical management of adrenocortical carcinoma. Br J Surg. 2017;104(4):358-376.

11. Kerkhofs TM, Verhoeven RH, Bonjer HJ, et al; Dutch Adrenal Network. Surgery for adrenocortical carcinoma in The Netherlands: analysis of the national cancer registry data. Eur J Endocrinol. 2013;169(1): $83-89$.

12. Simon G, Pattou F, Mirallie E, et al. Surgery for recurrent adrenocortical carcinoma: a multicenter retrospective study. Surgery. 2017;161(1): 249-256.

13. Erdogan I, Deutschbein T, Jurowich C, et al; German Adrenocortical Carcinoma Study Group. The role of surgery in the management of recurrent adrenocortical carcinoma. J Clin Endocrinol Metab. 2013;98(1): 181-191.

14. Libe R, Borget I, Ronchi CL, et al. Prognostic factors in stage III-IV adrenocortical carcinomas (ACC): an European Network for the Study of Adrenal Tumor (ENSAT) study. Ann Oncol. 2015;26(10): 2119-2125.

15. Kim Y, Margonis GA, Prescott JD, et al. Nomograms to predict recurrence-free and overall survival after curative resection of adrenocortical carcinoma. JAMA Surg. 2016;151(4):365-373.

16. Margonis GA, Kim Y, Prescott JD, et al. Adrenocortical carcinoma: impact of surgical margin status on long-term outcomes. Ann Surg Oncol. 2016;23(1):134-141.

17. Margonis GA, Kim Y, Tran TB, et al. Outcomes after resection of cortisol-secreting adrenocortical carcinoma. Am J Surg. 2016;211(6): 1106-1113.

18. Scollo C, Russo M, Trovato MA, et al. Prognostic factors for adrenocortical carcinoma outcomes. Front Endocrinol (Lausanne). 2016;7:99.

19. Reibetanz J, Jurowich C, Erdogan I, et al. Impact of lymphadenectomy on the oncologic outcome of patients with adrenocortical carcinoma. Ann Surg. 2012;255(2):363-369.

20. Gerry JM, Tran TB, Postlewait LM, et al. Lymphadenectomy for adrenocortical carcinoma: is there a therapeutic benefit? Ann Surg Oncol. 2016;23(Suppl 5):708-713.

21. Nilubol N, Patel D, Kebebew E. Does lymphadenectomy improve survival in patients with adrenocortical carcinoma? a population-based study. World J Surg. 2016;40(3):697-705.

22. Terzolo M, Baudin AE, Ardito A, et al. Mitotane levels predict the outcome of patients with adrenocortical carcinoma treated adjuvantly following radical resection. Eur J Endocrinol. 2013;169(3):263-270.

23. Loncar Z, Djukic V, Zivaljevic V, et al. Survival and prognostic factors for adrenocortical carcinoma: a single institution experience. BMC Urol. $2015 ; 15: 43$.

24. Maiter D, Bex M, Vroonen L, et al. Efficacy and safety of mitotane in the treatment of adrenocortical carcinoma: a retrospective study in 34 Belgian patients. Ann Endocrinol (Paris). 2016;77(5):578-585.

25. Postlewait LM, Ethun CG, Tran TB, et al. Outcomes of adjuvant mitotane after resection of adrenocortical carcinoma: a 13-institution study by the US Adrenocortical Carcinoma Group. J Am Coll Surg. 2016;222(4): 480-490.
OncoTargets and Therapy

\section{Publish your work in this journal}

OncoTargets and Therapy is an international, peer-reviewed, open access journal focusing on the pathological basis of all cancers, potential targets for therapy and treatment protocols employed to improve the management of cancer patients. The journal also focuses on the impact of management programs and new therapeutic agents and protocols on

\section{Dovepress}

patient perspectives such as quality of life, adherence and satisfaction. The manuscript management system is completely online and includes a very quick and fair peer-review system, which is all easy to use. Visit http://www.dovepress.com/testimonials.php to read real quotes from published authors. 